Review:

\title{
Challenges and Opportunities of Lean Remanufacturing
}

\author{
Jelena Kurilova-Palisaitiene and Erik Sundin \\ Division of Manufacturing Engineering, Department of Management and Engineering, Linköping University \\ SE-58381, Linköping, Sweden \\ E-mail: \{jelena.kurilova,erik.sundin\}@liu.se \\ [Received March 31, 2014; accepted August 4, 2014]
}

\begin{abstract}
Lean philosophy, which promotes business excellence through continuous improvement, originates from the Japanese car manufacturer, Toyota's Production System (TPS). An area where lean has not been fully explored is remanufacturing, a process that brings used products back to useful life. Remanufacturing is often a more complex process than manufacturing due to the uncertainty of process steps/time and part quality/quantity. This study explored remanufacturing by identifying its challenges and opportunities in becoming lean. The challenges of a lean remanufacturing system do not exceed its advantages. Although some researchers state that it is difficult or even impossible to apply lean principles to remanufacturing, this research utilizes lean as a continuous improvement philosophy that focuses on improving the remanufactured products' quality, process lead times, and inventory levels.
\end{abstract}

Keywords: lean, remanufacturing, product life cycle, continuous improvement

\section{Introduction}

Lean philosophy, which promotes business excellence through continuous improvement, originates from the Japanese car manufacturer, Toyota's Production System (TPS). Lean requires a gradual and long-term approach, and helps to maximize customer value and minimize waste. Working according to lean principles encourages companies to perceive the value of their business [1].

For several years, lean has been used only in manufacturing, but has recently spread to other areas as well, e.g., services and healthcare [2]. An area where lean has not been fully explored is remanufacturing. Remanufacturers bring used products back to useful life. The remanufacturing process consists of several steps such as inspection, cleaning, disassembly, reprocess, reassembly, and testing (Fig. 1).

From an environmental perspective, remanufacturing is more preferable than manufacturing and material recycling [4]. In particular, from a material resource perspective, remanufacturing becomes more desirable, especially with regard to closing the loop of hazardous materials [4].

Remanufacturing is often a more complex process than

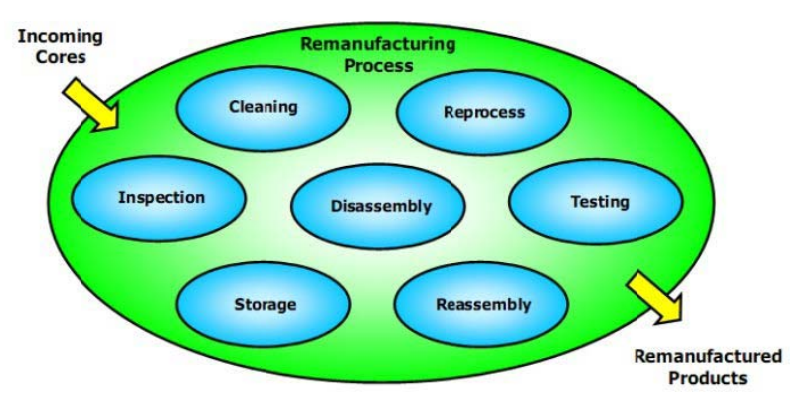

Fig. 1. A generic remanufacturing process [3].

manufacturing due to a higher level of uncertainty regarding process steps and time, as well as the unpredictability of the cores' (used products or their parts, returned by customers) quality and quantity [3]. However, remanufacturing has many similarities to manufacturing, and therefore applying lean principles to remanufacturing seems to be a logical step.

The growing need to deal with complexity and uncertainty challenges in order to sustain business is the major reason why many remanufacturers are interested in implementing lean at their facilities. Moreover, by analyzing manufacturers' achievements and their competitive advantage gained through lean manufacturing, remanufacturers are eager to investigate whether they have all the prerequisites to work with lean. Therefore, it is essential to study challenges and opportunities of lean remanufacturing.

\subsection{Aim}

The aim of this study is to determine the challenges and opportunities of lean remanufacturing. Moreover, a comparison between remanufacturing and manufacturing is performed in order to identify the possible areas of improvements for remanufacturers in their quest to become lean. Finally, a theoretical pathway to lean remanufacturing is developed.

\subsection{Research Methodology}

The research methodology consisted of a literature review, where research papers from databases, such as the Emerald, Scopus, Science Direct and Business Source Premier, were used. The search criterion was the phrase "lean remanufacturing." 
In total, 73 papers were found, among which 56 were from the Science Direct database. Among these, 37 papers, relevant to this research, were selected for further analysis. Subsequently, 31 papers, which focused on product development, service, and logistics, were disregarded. Moreover, the authors' previous knowledge of lean literature was used.

\section{Constraints in Remanufacturing}

\subsection{Identifying Remanufacturing Constraints}

Companies perform remanufacturing due to many economic, ecological, and/or policy reasons [5]. However, the remanufacturing business is rather young in comparison to manufacturing. Remanufacturers face major business challenges such as supply and demand imbalance, process inefficiency, and communication deficit. Although the scope of remanufacturing expands, it does not avoid the classic mistakes of an immature business.

One of the main remanufacturing constraints identified is the inability to reach the same level of product quality and lead time as the average manufacturer [6]. Other critical issues in remanufacturing come from shop floor constraints to customer satisfaction: insufficient quantity of the cores, increased product variability, process bottlenecks, and product design-related problems, as well as low employee skill levels.

In order to control the availability of the cores, Guide Jr. [7] introduced the concept of Material Recovery Rate (MRR). The intention was to make remanufacturing less dependent on variations in demand, quality, quantity, and timing of incoming cores. However, MRR does not help to control all remanufacturing issues. Remanufacturing is complex and difficult to manage due to a large number of uncertainties [8]. Although the core plays a central role, the remanufacturing process itself contributes to increased complexity. The issues of unpredictability, long processing and waiting times, unknown number of required process operations $[6,8,9]$, high levels of inventory, and information deficits regarding incoming cores [10] must be solved to make remanufacturing a profitable business.

Another critical issue is related to how uncertainty in the product's life cycle (Fig. 2) and technological changes influence the time and number of incoming cores.

The obstacles in the product return process and supply and demand constraints often force remanufacturers to cope with these problems alone, without any support from other actors in the same product life cycle $[12,13]$. In fact, reverse logistics challenges are closely related to the supply chain, communication, and collaboration challenges in the closed remanufacturing loop [14]. Poor information flow within the product life cycle, multiple networks that interface poorly with one another, and miscommunication concludes the list of identified remanufacturing constraints.

These major constraints in remanufacturing reveal that

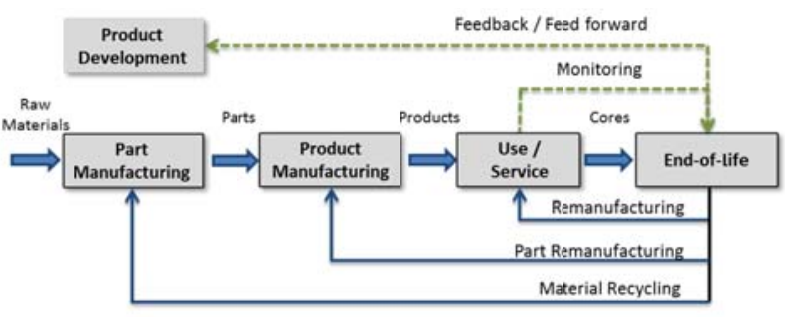

$\longrightarrow$ = Linear material flows $\longrightarrow$ = Reverse material flows $\quad \cdots=$ = Information flows

Fig. 2. Product life-cycle (adopted from Lindkvist and Sundin [11]).

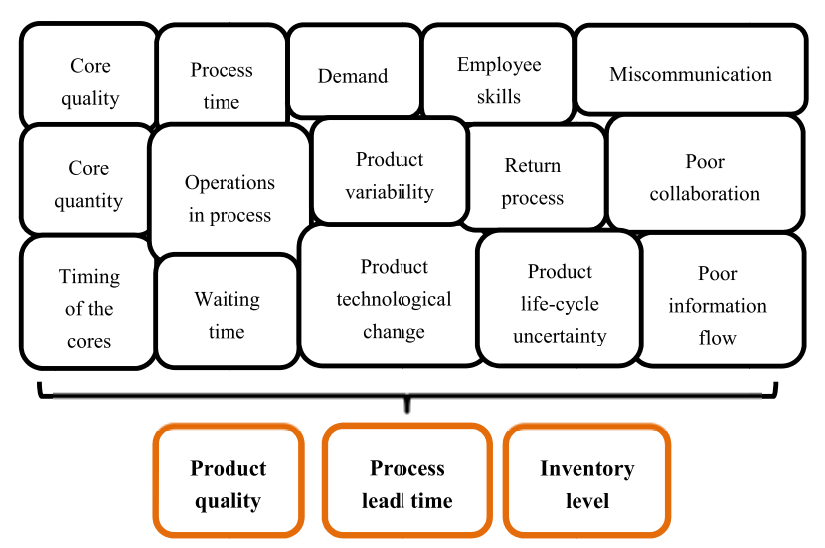

Fig. 3. Classification of major remanufacturing constraints (adopted from [15]).

remanufacturers depend on other, more mature product life cycle actors, who dictate business rules. Since remanufacturing is the last actor to join the product life cycle, it has to adapt to the market conditions and make a more obvious contribution. It is difficult to exist in the shadow of much bigger product life cycle actors, who started with the same challenges and business mistakes at least 100 years ago.

\subsection{Classification of Identified Constraints}

The 15 major remanufacturing constraints, identified from reviewed literature and described in the section 2.1., are summarized in Fig. 3. The interrelation between these constraints highlights three major categories of remanufacturing challenges: product quality, process lead time, and inventory level. A majority of the constraints can be addressed in two or even three groups of challenges.

\subsubsection{Product Quality}

Remanufacturing product quality covers three main areas:

- Incoming core quality

The questions arising here are:

How quickly and easily are core defects detected?

Are the cores delivered on time, in full demanded quantity, and of the right quality? 
Remanufacturing is typically the first instance to check the quality of the cores. Unlike manufacturing, each core item is inspected for quality defects. This quality control step takes up a large portion of remanufacturing time; however, core quality control enables value generation through the remanufacturing process [10]. Several methods are used to control core quality, such as core pre-inspection, documented performance monitoring during the whole use phase, and design for remanufacturing (DFRem) $[11,16]$. These methods can dramatically reduce the amount of resources (time, money, people, material) utilized in the first vital step in contemporary remanufacturing. Moreover, an improved pre-remanufacturing quality of acquired cores can boost the information feed forward and reduce variations in remanufacturing process.

The timely delivery of cores is essential for successful remanufacturing operations [17]. A new core return model like the Product Service System (PSS) can transform the remanufacturing challenges of uneven deliveries and supply - demand imbalance into sustainable longterm solutions [11]. Therefore, the amount of delivered cores is linked to the actual customer demand.

- Work in progress (WIP) quality

The questions arising here are:

How quickly and easily are the detected defects removed?

Are the spare parts ordered and delivered on time, in full demanded quantity, and of the right quality?

WIP products refer to the products that are collected from the incoming core inventory for further processing, but have not been completely remanufactured yet. WIP product quality depends mainly on three parameters: the core quality, spare part quality, and process quality.

Core quality is assured during the incoming core quality control step. Spare part quality is determined by the supplier, who is usually an original spare part manufacturer. When the remanufacturer keeps spare parts inventory, mainly from cannibalized cores, the quality control task shifts to the remanufacturer. The absence of the right type and quantity of spare parts, as well as delays in delivery, considerably harm the overall remanufacturing scenario. Therefore, timely spare part delivery of the right quality and quantity is the key to efficient remanufacturing operations.

However, the quality of cores and spare parts are not the only determinants, the remanufacturing process itself is a dominant one. Process quality refers to the capability of the process to add the right value at the right time. Process and product knowledge acquisition and application is challenging due to issues such as competition, the lack of awareness of such a need, lack of information exchange, and sometimes, lack of interest from other influential product life cycle actors [12-14].

- Remanufactured product quality

The questions arising here are:

To what extent does the remanufactured product perform like a new one?

Are the remanufactured products delivered on time, in full demanded quantity, and of the right quality?

The aim of remanufacturing is to deliver better or, at least, same as new product quality [12]. A quality check for each remanufactured item is a common practice in remanufacturing; however, some remanufacturing companies rely on their employees for step-by-step quality control during the remanufacturing process. Remanufactured products often have a service warranty and a return back option that complements the quality support provided by the remanufacturer.

In some cases, the need for remanufactured product quality surpasses the need for on-demand manufacturing and on-time delivery. Typically, remanufactured products meet customer quality expectations; however, this is often the only requirement remanufacturing has to satisfy. Despite a great potential for development, remanufacturing struggles to establish routines that guarantee timely and full delivery to the customer.

\subsubsection{Process Lead Time}

In the remanufacturing process, lead time typically starts from core acquisition and lasts until delivery to the customer. Process lead time consists of the actual time used to perform value and non-value added remanufacturing activities, and the waiting time between these activities.

\section{- Actual time for remanufacturing activities:}

- Time for value added activities

- Time for non-value added activities

To distinguish between value and non-value added activities, remanufacturers monitor their operations on a regular basis. It is important to eliminate/minimize the time spent on non-value added activities. For example, remanufacturing activities can be simplified, combined, or performed simultaneously.

\section{- Waiting time between activities}

The waiting time between activities is usually more than the time needed to perform the remanufacturing activity $[6,10]$. The core raw material waiting time comprises a large share of the total waiting time. Another significant waiting time is the time spent for spare parts delivery. However, the most costly waiting time is the time after the remanufactured products are transported to inventory until their delivery to the customer. The remanufacturing process lead time can be reduced by changing from pushing (forecasted demand) to pulling remanufacturing, where no cores are remanufactured before there is actual demand, and all spare parts are available on time [2].

The remanufacturing process lead time is larger than that in manufacturing $[3,7,10]$. Moreover, lead time is very variable and suspends improvements in the remanufacturing process. Issues regarding the length and variability of processing time partly arise from the previously mentioned product quality challenges. Another possible reason is a lack of improvement initiatives to generate 
improvements in material and information flows at the remanufacturing facility, and in connection to other product life cycle actors [3].

\subsubsection{Inventory Level}

There are three inventory-building areas in remanufacturing, associated with the transformation from a core to a finished product: cores raw material inventory, WIP inventory, and remanufactured product inventory.

- Cores raw material inventory - collected at the facility, inspected, and selected for further processing with a little work added

Remanufacturing has a high level of raw material, WIP, and finished product inventories $[10,18]$. The amount of incoming cores is determined by a few factors. The situation of unpredictable and uneven core delivery pushes remanufacturers to store vast amounts of inventory for a long time. Core inventory occupies a lot of space, causing operating complexity inside the facility. Unlike manufacturing, large core inventory is economically affordable due to the lesser cost of core acquisition. There is little value added to the core in the raw material inventory, since the core has only been collected and inspected. A new replenishment system with highly controlled inventory could be implemented to facilitate the efficient utilization and reordering of cores.

- WIP inventory - cores and spare parts with moderate work added

The WIP inventory levels tend to be rather low compared to manufacturing. Manufacturing throughput is higher than that in remanufacturing. Remanufacturing deals with several items at a time, while manufacturing companies employ automated processes that handle larger batch sizes. WIP inventory often emerges as a safety buffer to remanufacturing; however, it is more common that a large WIP inventory is caused due to poor product quality and uneven process lead time [7, 18].

- Remanufactured product inventory - inventory of ready to be distributed products, with maximum work added

Remanufactured product inventory is the most costly inventory, since so much value has been added. Sometimes, remanufacturing companies do not find a customer and have to hold this inventory. Moreover, overproduction leads to unnecessary resource utilization. This is a case of push manufacturing, where no actual demand is placed. For standard products, it is recommended to have some finished or pre-finished products. Thus, a system with a trigger that signals the initiation of the remanufacturing process is needed.

These three groups of constraints: product quality, process lead time, and inventory levels are commonly known by manufacturers, who actively work toward enhancing product quality, shortening and standardizing lead time, and minimizing inventory levels in the factories. Therefore, it is reasonable to examine the methods that manufacturers employ while dealing with similar challenges. One of the most widely used methods is to work with a philosophy of continuous improvements, also known as lean manufacturing or TPS. Furthermore, it is necessary to determine whether remanufacturing activities have the potential for lean improvements. For this purpose, an analysis of differences between manufacturing and remanufacturing with regard to lean is performed.

\section{What Remanufacturers can Learn from Manufacturers}

Sundin [3] highlights that, although the differences between manufacturing and remanufacturing systems are very significant, they still have more in common than any other business processes. Moreover, it is necessary to determine the extent of the lean gap between remanufacturing and manufacturing with regard to the "critical to successful business" categories (Table 1, where the score 1 corresponds to the least lean scenario and the score $4 \mathrm{de}$ fines the most lean case).

These 19 "critical to successful business" categories were collected during the literature review for this study. The categories are limited to the research performed in the areas of lean manufacturing and remanufacturing, and provide a solid platform for the comparison of important manufacturing and remanufacturing business indicators.

Stable and predictable revenue is a necessity for profitable remanufacturing operations [13, 19]. High operating costs have a negative effect on the amount of revenue generated from manufacturing. However, low remanufacturing processing and core acquisition costs do not necessary mean high profit; this can be attributed to the classified challenges of a remanufacturing business: product quality, process lead time, and inventory level (Fig. 3).

Faced with a very complex material flow, a minimal level of automation, insufficient remanufacturing volumes, and an ineffective planning horizon resulting in extensive lead time, remanufacturers are lagging behind manufacturers.

The difference between remanufacturers and manufacturers becomes more evident when comparing the level of uncertainty regarding the quantity, quality, and timing of incoming cores, spare parts, and remanufactured products.

Moreover, an absence of strong communication and information sharing channels, as well as a lack of collaboration between the different departments of the remanufacturing company and the rest of the product life cycle actors, supports the evidence that remanufacturers have a lot to learn from manufacturers, e.g., better product development.

The gap between manufacturing and remanufacturers with respect to lean can be seen in Fig. 4.

Manufacturers have not fully accomplished their transformation to the lean manufacturing system yet. Remanufacturers have great potential for improvement to reach the level manufacturers have today. In 17 of the 19 categories, remanufacturers are far behind manufacturers. The gap is relatively large and is likely to increase as man- 
Table 1. Scores comparing manufacturing and remanufacturing in 19 categories [15].

\begin{tabular}{|c|c|c|c|c|c|c|c|}
\hline \multirow{2}{*}{ Category } & \multicolumn{4}{|c|}{ Score } & \multirow{2}{*}{$\begin{array}{c}\text { Remanufacturing } \\
\text { Score value }\end{array}$} & \multirow{2}{*}{$\begin{array}{c}\text { Manufacturing } \\
\text { Score value }\end{array}$} & \multirow[t]{2}{*}{ References } \\
\hline & 1 & 2 & 3 & 4 & & & \\
\hline Revenue forecast & $\begin{array}{l}\text { Very unstable } \\
\text { Impossible to } \\
\text { forecast }\end{array}$ & $\begin{array}{l}\text { Variable } \\
\text { Difficult to forecast }\end{array}$ & $\begin{array}{l}\text { Stable } \\
\text { Possible to } \\
\text { forecast }\end{array}$ & $\begin{array}{l}\text { Very stable } \\
\text { Easy to forecast }\end{array}$ & 2 & 3 & {$[10,19]$} \\
\hline Operating costs & Very high & High & Low & Very low & 3 & 2 & {$[18,20]$} \\
\hline Competition & Very low & Low & High & Very high & 2 & 3.5 & [18] \\
\hline Material flow & Very complex & Less complex & Simple & Very simple & 1 & 2.5 & [3] \\
\hline Lead time & $\begin{array}{l}\text { Very long } \\
\text { Uncertain } \\
\text { Variable }\end{array}$ & $\begin{array}{l}\text { Long } \\
\text { Predictable }\end{array}$ & $\begin{array}{l}\text { Short } \\
\text { Predictable }\end{array}$ & $\begin{array}{l}\text { Very short } \\
\text { Standard }\end{array}$ & 1 & 3.5 & {$[3,7,10,18]$} \\
\hline Volume & Very low & Low & High & Very high & 1 & 3.5 & {$[7,10,12,20]$} \\
\hline Automation & Very low & Low & High & Very high & 1 & 3 & [12] \\
\hline Batch size & $\begin{array}{l}\text { Uncetain } \\
\text { Insufficient }\end{array}$ & $\begin{array}{l}\text { Certain } \\
\text { Insufficient }\end{array}$ & $\begin{array}{l}\text { Standard } \\
\text { Sufficient enough }\end{array}$ & $\begin{array}{l}\text { One-piece flow } \\
\text { Perfectly sufficient }\end{array}$ & 1 & 3.5 & {$[12]$} \\
\hline Planning horizon & $\begin{array}{l}\text { No freeze } \\
\text { window } \\
\text { Bad planning }\end{array}$ & $\begin{array}{l}\text { Ineffective freeze } \\
\text { window }\end{array}$ & $\begin{array}{l}\text { Effective freeze } \\
\text { window }\end{array}$ & $\begin{array}{l}\text { Very effective freeze } \\
\text { window combined with } \\
\text { JIT }\end{array}$ & 2 & 3.5 & {$[21,22]$} \\
\hline $\begin{array}{l}\text { Product } \\
\text { variation }\end{array}$ & $\begin{array}{l}\text { Very high } \\
\text { Difficult to } \\
\text { forecast }\end{array}$ & $\begin{array}{l}\text { High } \\
\text { Possible to forecast }\end{array}$ & $\begin{array}{l}\text { Customized } \\
\text { Possible to } \\
\text { forecast }\end{array}$ & $\begin{array}{l}\text { Customized } \\
\text { Module-based } \\
\text { Standard }\end{array}$ & 1 & 2.5 & $\begin{array}{c}{[3,7,12,18,} \\
23]\end{array}$ \\
\hline DFRem & Very low & Low & High & Very high & 1 & 1 & {$[3,12]$} \\
\hline Inventory level & Very high & High & Low & Very low & 2 & 2.5 & {$[10,18]$} \\
\hline Yield & $\begin{array}{l}\text { Very low } \\
\text { Uncertain }\end{array}$ & $\begin{array}{l}\text { Low } \\
\text { Predictable }\end{array}$ & $\begin{array}{l}\text { High } \\
\text { Predictable }\end{array}$ & $\begin{array}{l}\text { Very high } \\
\text { Predictable }\end{array}$ & 1 & 2.5 & {$[3,7,18]$} \\
\hline Quantity & Very uncertain & $\begin{array}{l}\text { Difficult, but } \\
\text { possible to forecast }\end{array}$ & Easy to forecast & $\begin{array}{l}\text { Standard } \\
\text { Stable }\end{array}$ & 1.5 & 3.5 & {$[7,12,24,25]$} \\
\hline Quality & $\begin{array}{l}\text { Uncertain } \\
\text { Bad }\end{array}$ & $\begin{array}{l}\text { Certain } \\
\text { Not sufficient }\end{array}$ & $\begin{array}{l}\text { Good } \\
\text { Sufficient }\end{array}$ & $\begin{array}{l}\text { Very good } \\
\text { Standard }\end{array}$ & 1.5 & 3.5 & {$[7,18]$} \\
\hline Timing & Very uncertain & $\begin{array}{l}\text { Difficult, but } \\
\text { possible to forecast }\end{array}$ & Easy to forecast & $\begin{array}{l}\text { Standard } \\
\text { Stable }\end{array}$ & 1 & 3 & [7] \\
\hline Communication & $\begin{array}{l}\text { Not } \\
\text { functioning }\end{array}$ & $\begin{array}{l}\text { Functioning in a } \\
\text { shop floor scope }\end{array}$ & $\begin{array}{l}\text { Functioning in a } \\
\text { company scope }\end{array}$ & $\begin{array}{l}\text { Functioning in a } \\
\text { product life-cycle scope }\end{array}$ & 1 & 3 & [26] \\
\hline Collaboration & $\begin{array}{l}\text { Not } \\
\text { functioning }\end{array}$ & $\begin{array}{l}\text { Functioning in a } \\
\text { shop floor scope }\end{array}$ & $\begin{array}{l}\text { Functioning in a } \\
\text { company scope }\end{array}$ & $\begin{array}{l}\text { Functioning in a } \\
\text { product life-cycle scope }\end{array}$ & 1 & 3 & {$[26]$} \\
\hline Sharing risk & $\begin{array}{l}\text { Not } \\
\text { functioning }\end{array}$ & $\begin{array}{l}\text { Functioning in a } \\
\text { shop floor scope }\end{array}$ & $\begin{array}{l}\text { Functioning in a } \\
\text { company scope }\end{array}$ & $\begin{array}{l}\text { Functioning in a } \\
\text { product life-cycle scope }\end{array}$ & 1 & 3 & [26] \\
\hline
\end{tabular}

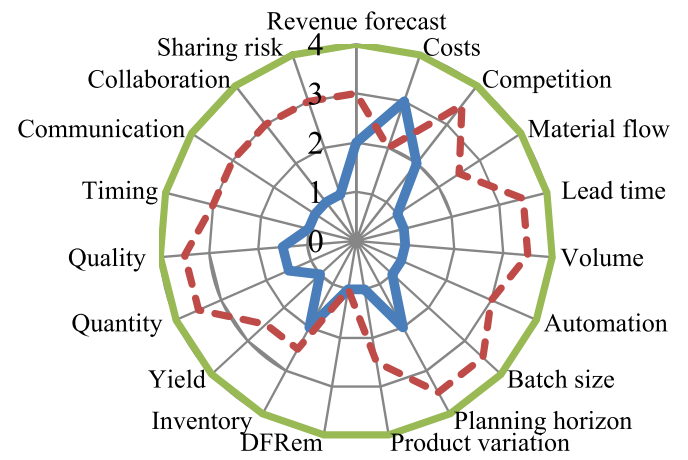

Remanufacturing $-\infty$ Manufacturing $\rightleftharpoons$ Lean

Fig. 4. Gap between manufacturing and remanufacturing with respect to lean (based on scores presented in Table 1).

ufacturers are continuously working on improvements.

The only characteristic where remanufacturers are ahead of manufacturers is in the area of cost. As stated previously, low costs do not indicate a state-of-the-art business, but cheap raw material.

At the same time, the only characteristic where manufacturers perform poorly is DFRem. The DFRem characteristic represents the product development initiative, or its absence, with regard to designing products that are suitable for remanufacturing. This characteristic brings manufacturing and remanufacturing design issues closer to each other. Manufacturers tend to increase product variation, and this means that remanufacturers will face more challenges in the future.

The situation can become even worse if the inefficient communication and collaboration between the remanufacturers and other product life cycle actors continues. Risk sharing is not practiced at all, since no system of shared values has been developed in the product life cycle.

One reason for the higher score for manufacturing is their achievements in developing an efficient manufacturing system and a collaborative company culture of continuous improvement. As mentioned before, a lean manufacturing system with its operational principles and strategic philosophies enables manufacturers to achieve the desired improvement.

Manufacturers are the pioneers of lean transformations; today, not only entire manufacturing facilities, but also global corporations work according to lean principles and philosophy. These companies gradually succeeded in enhancing product quality, reducing lead time, and controlling inventory level. Lean principles and tools can help remanufacturers gain a competitive advantage, as they did 
for manufacturers.

\section{Lean in Remanufacturing}

Earlier attempts to apply lean in remanufacturing were challenged by the major remanufacturing constraints (Fig. 3). Previous studies claim that stable demand and supply are prerequisites for working with lean. Some researchers have expressed their deep concern about the transformation of lean manufacturing systems into lean remanufacturing systems; they claim that establishing the types of lean and mass customization systems that manufacturers depend on is practically impossible [10].

However, the skepticism regarding lean implementation in remanufacturing has driven researchers to investigate the possibility of applying lean to remanufacturing. Since the start of remanufacturing activities, researchers and practitioners have developed different methods for planning, scheduling, and controlling remanufacturing systems. For example, Guide Jr. [27] proposed the drumbuffer-rope planning system, which reminds remanufacturers about the pull system, actively used by lean manufacturers.

Moreover, the potential for applying lean principles to remanufacturing has been noted by several researchers (Table 1). The definite need for improvements in the remanufacturing business was studied by Sundin [3]. He identified the need for remanufacturing to gain efficiency through lean manufacturing concepts such as lowering the high level of inventories, material movements, product flow, and use of space.

Pawlik et al. [28] observed a positive effect of lean on remanufacturing. Fargher [29] provided an explicit finding on the application of lean tools in remanufacturing. Moreover, Jacobs et al. [30] introduced lean as a tool for waste reduction in remanufacturing, and stated that a signal to start remanufacturing is customer pull. Therefore, lean can help remanufacturers to decrease lead time and costs, increase productivity, enhance quality, and ensure continuous flows.

Östlin and Ekholm [31] provided practical evidence on the benefits of lean principles in remanufacturing. In their research, the lean concept was actively treated as a set of tools and principles that enable remanufacturers to increase productivity, decrease lead time and costs, enhance quality, develop flexibility in operations, reduce setup time, and rearrange the workshop layout.

Hunter and Black [32] provided another example on the successful implementation of lean tools in cellular remanufacturing, and highlighted four critical control functions in lean manufacturing: quality, production, process, and inventory.

Kucner [33], in his long-term observations of lean principles in remanufacturing, concluded that there is great potential to adjust the application of lean tools depending on the levels of product variety and volume in remanufacturing. Kanikula and Koch [34] developed nine Kanban replenishment scenarios including inventory man- agement, pull system, First In First Out (FIFO), and supermarket-controlled buffers in remanufacturing.

In previous research regarding the application of lean manufacturing philosophy and principles to remanufacturing, it was found that lean indeed helps remanufacturers to enhance product quality, shorten lead times, and control the inventory level. Moreover, lean provides a guideline for value creation in every process.

However, all these attempts to apply lean principles and tools in remanufacturing belong to the area of "operational lean manufacturing" [35]. In this case, lean is usually seen as a collection of different improvement initiatives and projects to improve separate remanufacturing problems one at a time. There is usually a weak association between lean implementation and a company's managerial strategy. Here, the lean concept is usually mistrusted by the one who executes it, thus destroying any basis for continuous improvement.

Therefore, lean is not only a set of tools, but a company's culture and management philosophy as well. This finding is in contrast to operational companies, which work on a strategic lean philosophy level and succeed in incorporating lean thinking in their corporate culture [35]. These companies usually create their own operation management systems by adopting lean thinking, and transforming the lean practical examples of manufacturing pioneers. Companies tend to move gradually from the lean operational level to the strategic level. However, some companies never develop a lean philosophy and culture, and therefore fail to transform into a profitable lean company. Lean is a philosophy of gradual improvement, and this fact should not be underestimated by its implementers.

The strategic level of lean application is the missing part of research regarding lean implementation in remanufacturing. This is why the long-term impact of lean application in remanufacturing is so difficult to determine. It is necessary to incorporate the lean culture of continuous improvement and lean values into the remanufacturing business, and manufacturers should help remanufacturers in achieving this goal.

\section{Transformation to Lean Remanufacturing}

A pathway for remanufacturing companies' striving toward lean can be created by following the Lean remanufacturing pyramid (Fig. 5). The Lean remanufacturing pyramid describes the challenges and perspectives for improvements in material and information flows in remanufacturing. Lean remanufacturing is achieved when the company accomplishes the third level of transformation.

The Lean remanufacturing pyramid presents three levels of remanufacturing transformation to lean. These levels are placed on a time axis that shows only one direction for lean transformation with no start or end. The Lean remanufacturing pyramid brings a comprehensive approach to lean remanufacturing and emphasizes the importance of material and information flows' improvements in the 


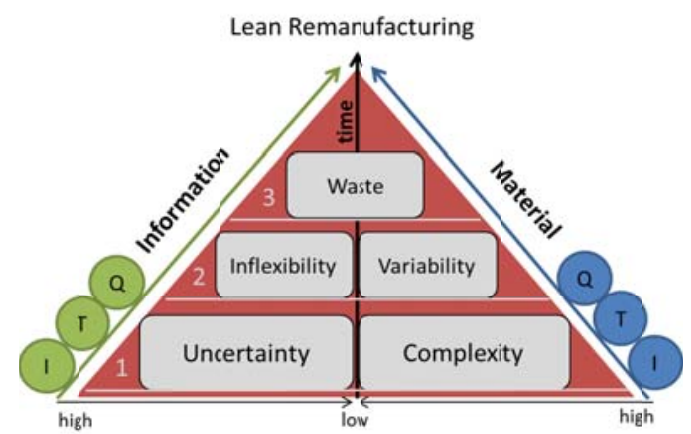

Fig. 5. Lean Remanufacturing Pyramid, where Q - Product quality, T - Process lead time, and I - Inventory level.

transformation to lean.

Lean remanufacturing transformation starts simultaneously from bottom of both the material and information axis, where QTI (product quality, process lead time, and inventory level) are placed, and moves up through level 1,2 , and 3 until lean remanufacturing is reached. Improvements in QTI during the first level of external lean challenges is possible when the level of uncertainty and complexity in remanufacturing is reduced, which was found to be the largest challenges according to Lundmark et al. [8]. In the second level of internal lean challenges, remanufacturing focuses on reducing material and information variability and inflexibility. However, in order to become lean, remanufacturing has to overcome the third level of challenges, that is, lean remanufacturing waste. Rising up along the material and information axis remanufacturing comes closer to ideal lean remanufacturing scenario. Striving for perfection through continuous improvements will make this journey a long-term one.

\subsection{Level 1: External Lean Challenges}

Uncertainty refers to the difficulties in predicting remanufacturing activities. Information uncertainty reflects a weak collaboration with other powerful product life cycle actors. A lack of information inhibits remanufacturing progress and this stagnation escalates along with complexity in the remanufacturing process, related to material supply and demand [8].

To overcome the uncertainty level, information flows need to be established in a reverse logistic system to reflect the need for returns and demand [7,36]. Information deficits regarding the incoming cores' quality, quantity, and timing, diminish the remanufacturer's ability to respond to the internal and external customers' demand. Timely and accurate core information would enable remanufacturers to control the remanufacturing process actively, providing greater outcomes to the end-customers. With information streaming down to remanufacturers, all product life cycle actors would gain access to the system of shared values.

Complexity refers to the difficulties in operating due to the vast amount of product life cycle variables (Fig. 3). A lack of material resources (cores and spare parts) makes remanufacturing very complicated. These scarce or absent resources limit remanufacturing throughput [8].

Usual bottlenecks, sudden material starvation, and inefficient equipment deployment create considerable complexity in the remanufacturing process [7]. Remanufacturing complexity in operations planning, controlling, and management partly contributes to information uncertainty.

Cost versus price and return versus demand are further complicated by the need for a special information system for material handling [37].

Additional difficulties are stochastic remanufacturing operations and destructive material processing environment, including complex resource, people, and inventory management [7, 27, 37].

The usual dimensions used to characterize remanufacturing complexity are cores and product complexity; therefore, products with a high level of complexity require a more flexible control system [37].

Product design, which only focuses on manufacturing, often makes it difficult and economically infeasible to remanufacture those products. Therefore, reducing product complexity would require considerable efforts in designing products that are suitable for remanufacturing. Moreover, this would enable the standardization of remanufacturing operations [37].

\subsection{Level 2: Internal Lean Challenges}

Inflexibility refers to the ability to foresee demand, but the inability to respond. Information exchange routes with other product life cycle actors are established; however, internal inflexible information flows prohibits customers from getting what they want. This refers to providing the wrong quality and/or quantity, late delivery, and an absence of a constructive dialog with the customers.

Flexibility can be defined as the capability and ease of systems to change from one state to another [38]. Inflexibility is the inability to respond effectively to customers' demand, leading to the occurrence of additional costs [2].

After improving communication flows, remanufacturing facilities can handle the incoming cores and remanufactured products; however, an increase in operational flexibility is required. A quick and efficient feedback and feed-forward data transmission system can secure a justified degree of flexibility.

According to Östlin et al. [13], flexibility is necessary for the efficient response to complexities and uncertainties in the environment. Information flexibility can be improved by investing in multi-skilled employees in the various operations, for better internal collaboration. Operational flexibility refers to the capability for fast model reconfiguration, selection among different options/alternatives, adjustments in process capacity, frequency, remanufacturing volume, and resource utilization, as well as product mix [39].

Variability means that it is possible to operate, but difficult to follow standards due to process instability and many internal material deviations. Process and material 
instability are any deviations from the standards of cores, spare parts, process, employee skills, and the operational environment $[2,3,8]$. Internal material variability is a sign of unsolved issues of external lean challenges and implies the need to focus on material standards for the entire product life cycle.

Remanufacturing operations are highly variable in the number of operations that must be performed and their sequence, as well as the quantity and quality of cores. Moreover, remanufacturing workstations are subject to extreme fluctuations in material inventory due to stochastic routings and highly variable processing times [27]. Reduction in material variability would lead to operational standards and increase process repeatability.

\subsection{Level 3: Lean Remanufacturing Waste}

Lean Remanufacturing Waste originates from the seven lean wastes [2], and delivers the possibility to respond to and follow standards, but with some difficulties in value creation. Waste usually implies the utilization of wrong or explicit methods. In Lean, waste refers to any work that does not add value, and remanufacturing waste refers to the usage of resources beyond what is needed to meet customers' requirements (waiting, inventory, motion, over-processing, transport, overproduction, rework, and scrap) [2]. The most contradictory among remanufacturing wastes is inventory. Inventory level reduction in manufacturing is one of the key lean goals. In remanufacturing, uncontrolled inventory causes problems and must therefore be systemized and controlled. Inventory control involves the elimination and reduction of unnecessary material, and an increase in the required cores and spare parts. This is needed to meet demand and increase remanufacturing throughput.

\section{Conclusions}

This research revealed the need to improve the vital indicators of the remanufacturing business. The major remanufacturing challenges were identified and classified into three categories: product quality, process lead time, and inventory level challenges.

Lean manufacturing principles and philosophies continually deal with these three categories of challenges. This finding leads to the assumption that lean can help remanufacturing to improve its business indicators, and therefore gain a competitive advantage, as it did for manufacturers. Since the remanufacturing business has many similarities with manufacturing, it is reasonable to make a comparison between manufacturers and remanufacturers with respect to lean.

Remanufacturers have opportunities to be lean in 19 identified categories (Fig. 4). The gap between remanufacturers and manufacturers appears to be big. In 17 of the 19 vital characteristics for successful business, remanufacturers are behind manufacturers. The only characteristic where remanufacturers have a leading position is cost. However, low cost does not result in high revenue and mainly indicates cheap raw material, i.e., returned cores. Therefore, the gap between remanufacturers and manufacturers provides evidence that remanufacturers can learn a lot from manufacturers, while becoming leaner.

The advantages of lean remanufacturing were discussed and opportunities to be lean were presented. A theoretical pathway toward lean remanufacturing was developed with a focus on three transformation levels: external lean challenges, internal lean challenges, and lean remanufacturing waste. Findings from industrial evidence and academic research on lean remanufacturing provide a solid base for the further investigation of lean application benefits to remanufacturing. However, lean remanufacturing principles and methods should not be underestimated, but rather modified in order to suit remanufacturing business needs. Moreover, a lean remanufacturing deployment strategy should avoid implementing lean on a project basis, but rather treat it as a company culture of continuous improvement.

\section{Future Research}

The findings of this research will contribute to the future development of a lean model with principles and philosophies designed exclusively for remanufacturing.

\section{Acknowledgements}

The authors would like to thank the Swedish Governmental Agency for Innovation Systems (VINNOVA) for financing this research.

\section{References:}

[1] N. Modig and P. Åhlström, "This is Lean - resolving the efficiency paradox," Rheologica Publishing, Stockholm, 2012.

[2] J. Womack and D. T. Jones, "Lean Thinking," Simon \& Schuster, New York, 1996.

[3] E. Sundin, "How can Remanufacturing Processes become Leaner?" Proc. of $13^{\text {th }}$ CIRP Int. Conf. on Life Cycle Engineering, Leuven, Belgium, May 31 - Jun. 02, pp. 429-434, 2006.

[4] E. Sundin and H. M. Lee, "In what way is remanufacturing good for the environment?" Proc. of the $7^{\text {th }}$ Int. Symp. on Environmentally Conscious Design and Inverse Manufacturing (EcoDesign-11) Nov. 30 - Dec. 2, Kyoto, Japan, pp. 551-556, 2011.

[5] J. Östlin, E. Sundin, and M. Björkman, "Business Drivers for Remanufacturing," the Proc. of $15^{\text {th }}$ CIRP Int. Conf. on Life Cycle Engineering, The University of New South Wales, Sydney, Australia, 17-19 Mar., pp. 581-586, 2008.

[6] R. Hammond, T. Amezquita, and B. Bras, "Issues in the Automotive Parts Remanufacturing Industry - A Discussion of Results from Surveys Performed among Remanufacturers," Systems Realization Laboratory, The George W. Woodruff School of Mechanical Engineering, Georgia Institute of Technology, Atlanta, USA, pp. 1-24, 1996.

[7] V. D. R. Guide Jr., "Production planning and control for remanufacturing: Industry practice and research needs," J. of Operations Management, Vol.18, Issue 4, pp. 467-483, 2000.

[8] P. Lundmark, E. Sundin, and M. Björkman, "Industrial Challenges within the Remanufacturing System," Proc. of Swedish Production Symp., Dec. 2-3, Göteborg, Sweden, pp. 132-138, 2009.

[9] A. E. E. Van Nunen Jo and R. A. Zuidwijk, "E-Enabled ClosedLoop Supply Chains," California management review, Vol.46, No.2, pp. 40-54, 2004. 
[10] M. A. Seitz and K. Peattie, "Meeting the Closed-Loop Challenge: The Case of Remanufacturing," California management review, Vol.46, No.2, pp. 74-89, 2004.

[11] L. Lindkvist and E. Sundin, "The Use of Product Life-Cycle Information in a Value Chain including Remanufacturing, Reengineering Manufacturing for Sustainability," Proc. of the $20^{\text {th }}$ CIRP Int. Conf. on Life Cycle Engineering, Singapore, 17-19 Apr., pp. 621-626, 2013.

[12] R. Steinhilper, "Remanufacturing - The ultimate form of recycling," Fraunhofer IRB Verlag, Stuttgart, 1998.

[13] J. Östlin, E. Sundin, and M. Björkman, "Product Life-cycle Implications for Remanufacturing Strategies," J. of Cleaner Production, Vol.17, Issue 11, pp. 999-1009, 2009.

[14] Inmar Reverse Logistics, "Special Report on Automotive Aftermarket Reverse Logistics Opportunities," Mema Information Services Council, Inmar, Winston-Salem, USA, 2009.

[15] J. Kurilova-Palisaitiene and E. Sundin, "Remanufacturing: Challenges and Opportunities to be Lean," Proc. of $8^{\text {th }}$ Int. Symp. on Environmentally Conscious Design and Inverse Manufacturing (EcoDesign 2013), Jeju Island, South Korea, Dec. 4-6, pp. 2013.

[16] H. Hiraoka and A. Tanaka, "Simulator for Reuse of Mechanical Parts with Network Agents," Int. J. of Automation Technology, Vol.3, No.1, 2009.

[17] S. Lind, D. Olsson, and E. Sundin, "Exploring inter-organizational relationships in automotive component remanufacturing," J. of Remanufacturing, Vol.4, No. 5, 2014.

[18] S. Dowlatshahi, "A strategic framework for the design and implementation of remanufacturing operations in reverse logistics," Int J. of Production Research, Vol.43, Issue 6, pp. 3455-3480, 2005.

[19] T. Amezquita, R. Hammond, and B. A. Bras, "Issues in the Automotive Parts Remanufacturing Industry: Discussion of Results from Surveys Performed among Remanufacturers," Int. J. of Engineering Design and Automation - Special Issue on Environmentally Conscious Design and Management, Vol.4, 1, pp. 27-46, 1998.

[20] J. T. Mentzer, W. DeWitt, J. S. Keebler, M. Soonhoong, N. W. Nix, C. D. Smith, and Z. G. Zacharia, "Definition of Supply Chain management," J. of Business Logistics, Vol.22, Issue 2, pp. 21-26, 2001.

[21] B. Ashenbaum, "Designing the supply chain for production and after market needs," Critical Issues report, CAPS: Center for Strategic Supply Research, 2006.

[22] M. M. Davis and J. Heineke, "Operations Management - Integrating Manufacturing and Services," McGraw Hill, New York, 2005.

[23] J. Olhager, "Produktionsekonomi," Studentlitteratur, Lund, Sweden, 2000.

[24] Y. Umeda, S. Kondoh, and S. Takashi, "Proposal of "Marginal Reuse Rate" for Evaluating Reusability of Products," Int. Conf. on Engineering Design, Melbourne, Aug. 15-18, 2005.

[25] A. Atasu and L. N. Van Wassenhove, "Outsourcing Remanufacturing under Finite Life Cycles: Operational and Tactical Issues," ZfBSpecial Issue 3, pp. 77-94, 2005

[26] A. Phelan, J. Griffiths, and S. Fisher, "Pushing Worldwide Aftermarket Support of Manufactured Goods," Managing Service Quality, Vol.10, Issue 3, pp. 170-177, 2000.

[27] V. D. R. Guide Jr., "Production economics - Scheduling with priority dispatching rules and drum-buffer-rope in a recoverable manufacturing system,” Int. J. of Production Economics, Vol.53, pp. 101116, 1997.

[28] E. Pawlik, W. Ijomah, and J. Corney, "Current State and Future Perspective Research on Lean Remanufacturing - Focusing on the Automotive Industry," IFIP Advances in Information and Communication Technology, Vol.397, pp. 429-436, 2013

[29] J. S. W. Jr. Fargher, "Lean Manufacturing and Remanufacturing implementation tools," Missouri Enterprise, University of Missouri, Rolla, MO, 2006.

[30] F. R. Jacobs and R. H. Chase, "Operations and supply management - the core," McGraw Hill, Boston, 2001.

[31] J. Östlin and H. Ekholm, "Lean production Principles in Remanufacturing - A Case Study at a Toner Cartridge Remanufacturing," Proc. of IEEE Int. Symp. on Electronics and the Environment, Orlando, USA, May 7-10, 2007.

[32] S. L. Hunter and T. J. Black, "Lean Remanufacturing: a cellular case study," J. of Advanced Manufacturing Systems, Vol.6, No.2, pp. 129-144, 2007.

[33] R. J. Kucner, "A Socio-technical study of lean manufacturing deployment in the remanufacturing context," Dissertation, The University of Michigan, 2008

[34] T. Kanikula and T. Koch, "Methodology of Designing Disassembly and Reassembly Processes Using Lean Thinking Approach," Advances in Production Management Systems New Challenges, New Approaches, pp. 11-18, 2011.
[35] P. Hines, M. Holweg, and N. Rich, "Learning to evolve: A review of contemporary lean thinking," Int. J. of Operations \& Production Management, Vol.24, 10, pp. 994-1011, 2004.

[36] K. Inderfurth, "Impact of uncertainties on recovery behavior in a remanufacturing environment: A numerical analysis," Int. J. of Physical Distribution and Logistics Management, Vol.35, 5, pp. 318-336, 2005.

[37] V. D. R. Jr. Guide, V. Jayaraman, and J. D. Linton, "Building contingency planning for closed-loop supply chains with product recovery," J. of operations management, Vol.21, Issue 3, pp. 259-279, 2003.

[38] N. Slack, "The flexibility of manufacturing systems," Int. J. of Operations \& Production Management, Vol.25, 12, pp. 1190-1200, 2005

[39] C. Bai and J. Sarkis, "Flexibility in reverse logistics: a framework and evaluation approach," J. of Cleaner Production, Vol.47, pp. 306$318,2013$.

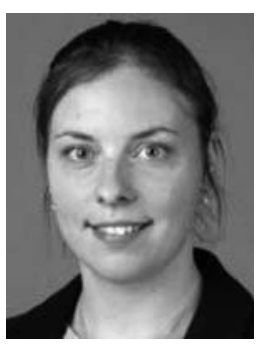

\section{Name:}

Jelena Kurilova-Palisaitiene

Affiliation:

Ph.D. Candidate, Division of Manufacturing Engineering, Linköping University

Address:

Campus Valla, Linköping University, 58183 Linköping, Sweden

\section{Brief Biographical History:}

2008- Bachelor in Economics, Klaipeda University, Lithuania

2010- Master in Industrial Engineering and Management, Linköping University

2013- Lean Production System Junior Project Manager, Aurubis Sweden AB, Finspång, Sweden

2014- Visiting Ph.D., Fraunhofer IPT, Aachen, Germany

Now- Ph.D. Candidate: Lean Remanufacturing, Linköping University, Sweden



Name:
Erik Sundin

Affiliation:

Associate Professor, Linköping University

Address:

Campus Valla, Linköping University, 58183 Linköping, Sweden

Brief Biographical History:

1999-2004 Ph.D. Candidate. Thesis title: Product and Process Design for Successful remanufacturing

2004- Associate Professor in Sustainable Manufacturing

Main Works:

- "Making Functional Sales Environmentally and Economically Beneficial through Product Remanufacturing," J. of Cleaner Production, Vol.13, Issue 9, pp. 913-925, 2005.

- "Importance of Closed-Loop Supply Chain Relationships for Product Remanufacturing," Int. J. of Production Economics, Vol.115, Issue 2, pp. 336-348, 2008.

- "Product Life-cycle Implications for Remanufacturing Strategies," J. of Cleaner Production, Vol.17, Issue 11, pp. 999-1009, 2009.

- "Product design for product/service systems - design experiences from Swedish industry," J. of Manufacturing Technology Management, Vol.20, Issue 5, pp. 723-753, 2009.

- "Design for automatic end-of-life processes," Assembly Automation, Vol.32, Issue 4, pp. 389-398, 2012.

Membership in Academic Societies:

- International PSS Design Community (www.pssdesignresearch.org) 